\title{
Discussion
}

\section{Public Reactions to Xenotransplantation}

\author{
Stellan Welin and Anders Persson
}

The aim of this paper is to discuss public and political reactions to xenotransplantation (transplantation of cells, tissues and organs between species; in this paper specially from pigs to humans) and try to understand what is happening. After a short overview of xenotransplantation from immunological and infection aspects and description of some regulatory work, the focus will be turned to what is known about public attitudes and feelings towards xenotransplantation. Some instances where the discussion of xenotransplantation has reached the political arena are also discussed.

At the end of the paper an attempt is made to interpret and understand how the reactions of the public are formed. Somefurther areas of interest for astudy of public understanding of science are suggested.

\section{Shortage of Organs for Transplantation}

The advent of human allotransplantation (transplantation of cells, tissues and organs between humans) in the 1950s and its combination with immunosuppressivedrugs, introduced on a bigscale in the 1980s, meant a dramatically increased chance of survival for many patients, who earlier were doomed to die. The success rate has improved and the cost has declined. Renal transplantation, for example, is todayan established procedure and in many cases better (and cheaper) than dialysis. However, there is a serious shortage of organs for transplantation and - even if some countries like Spain manages to harvest more human organs - it is difficult to see a large increase in the near future. Even if it might be possible to harvest more hu- 
man organs through intensive public information campaigns the demand for organs for transplantation is rapidly increasing. It will be very difficult to bridge the gap between demand and supply. Using animals as donors - which is the idea behind xenotransplantation - could be one way of overcoming this shortage.

There are also troubling ethical and psychological problemsaround the procurement of organs. In most countries, to harvestcadaveric organs either a form of known intention to donate from the deceased or some form of consent from the relatives are needed. (The concept of brain death must be used as the criterion for death.) This consent can be difficult to obtain, hospital staff may feel uneasy about raising the question of donation just after death has occurred and the relatives are in grief and have difficulties to weight the pros and cons in the acute situation. The problems are of course aggravated by the fact that the "perfect" donor is an (otherwise) healthy young person dead from brain injury; young persons do not normally plan for their death and therelatives areshocked and in grief by the sudden death.

\section{Using Animal Donors: a Way to Increase the Supply of Transplants}

Use of animal organs for transplantation, that is xenotransplantation, would give a boost to the number of organs available. If the physiological and immunological compatibility problems are overcome, a nearly unlimited supply of organs, tissues and cells for transplantation would exist. Furthermore, the transplantation can be planned and controlled, the donor screened in good time for various pathogens and so on.
Thisis in sharp contrast to theallotransplantation case, where the transplantation often must be performed within a few hours of the death of the donor.

At present, it is not known if one will be successful in overcoming the physiological and immunological compatibility problems of transplantation from non-human animalsto humans. Progress has been made in recent years due to application of genetic technologies and the advent of potent immunosuppressive drugs. This has triggered a new interest in xenotransplantation. At present, the pig is the designated donor animal.

This is partly for physiological reasons; pig organs are believed to besimilar enough to the human organs. Furthermore, pigs are of approximately the same size as humans. At the same time from an evolutionary point of view pigs arenot asclose relatives as primates and the risk for transmission of disease is believed to be considerably lower. After all, theHIV epidemicsisbelieved to have started from monkeys.

Most monkeys are also too small for organ compatibility in a physiological sense. Apart from this problem, there is low social acceptance of using primates and higher apes as donors. After all, we eat pigs but usually not primates. Most primates are also threatened by extinction.

On the other hand, when pigs are preferred as being not so closely related to humans as for examples apes, there are more severe rejection problems. A pig organ (if not modified or treated) in contact with human blood will undergo what is called hyperacute rejection (HAR) in just a few minutes. This is a result of human antibodies binding to an antigen on the surface of endothelial 
porcine cells. In very short time this will give rise to a cascade of other reactions resulting in clotting and death of the organ. With the help of the genetically modified pig (the DAF pig) HAR can be avoided. The contact between human blood and endothelial cells from the DAF-pigs will not trigger the cascade of events resulting in HAR. The DAF-pig are a first step towards xenotransplantation (Platt, 1998)

Other rejections are however known to happen later on in xenotransplantation. Experiments with xenotransplantation between species without this special incompatibility give rise to other delayed rejections not yet completely understood. Research is going on aiming at understanding these further delayed rejections. ${ }^{1}$

Bigpharmaceutical firms like Novartis have invested much in xenotransplantation. Novartis is now the owner of Imutran in Cambridge, UK, whereDavid White and his collaborators developed the transgenic DAF pig. Novartis is said to be prepared to spend up to 1 billion dollar in the near future to develop the technique. (Butler, 1998). Other pharmaceutical companies are also involved. In contrast to the allotransplantation case, where selling and buying of human organs are illegal, the pig organ market will (probably) be fully commercial. Rich people will be able to buy their pig organ and do not haveto wait. On the other hand, if xenotransplantation is successful this might mean an end to the illegal business in human organs.

\section{The Threat of Infections and Proposal for Moratorium}

The possibility of transmission of Por- cine Endogenous Retrovirus (PERV) to human cells in vitro has recently been discovered.( Patience et al., 1997) Can this happen in the transplantation situation? Further, if a transplanted patient isinfected, can these retroviruses mutate in their new human surroundings and be transformed into dangerous human pathogens that may cause an epidemic? PERV cannot be eliminated from the pigsas the virus is incorporated into the porcinegenomeand it looks likeall pigs do have PERV. ${ }^{2}$ The risk of infection by PERV, mutation and a widespread infection can thus not be ruled out a priori. The most probable effect of a PERV infection is oncogenic (increased risk of cancer) and general immunosuppression (like the HIV infection). (Denner, 1998)

Is this a serious risk? Obviously, if the worst case materialise and we have a new deadly plague, we will all agreethat it was a very big risk indeed and that, sad to say, only a very few took it seriously. The problem is that we do not know the probabilities for the various outcomes and all assessments have to be made on the basis of our present knowledge, which we know is incomplete. Assessments of risk should at least contain two parts, onestating the particular possible outcomes and another saying something about the likelihood of a specific outcome. To these considerations one must add some deliberation on the social acceptability, the ethical issues and so on. The most problematic kind of risk to handleis when the worst possiblecase is very serious and grave but the likelihood is (assumed to be) low.

The discovery of the infection risk of PERV has led Fritz Bach and some other leading proponents of the xenotrans- 
plantation concept to demand a moratorium on clinical trials for xenotransplantation. (Bach et al., 1998) It seems that Bach and his co-writers regard the case of xenotransplantation as unique; never before has it been attempted to incorporatelivinganimal organs, cellsor tissue in the human body on a permanent basis. The worst case is of course if thereis a mutation of a porcine virus that turns it into a murderous human one that spreads in the whole human population.

Bach et al. are recommending two moratoriums: onebeforeany clinical trials of xenotransplantation start and one after the first clinical trials - beforemoving to clinical use. Thefirst might besaid to be implemented at present more or less. In most countries no clinical xenotransplantation takes place and work is going on to construct a framework for clinical trials. There are however some cell xenotransplantation studies going on in the US at present. Whether or not there has been enough public deliberation taking place seems to be a matter of discussion also among Bach and his co-writers. One of them has gone public and claims that the consultations FDA and other agencies have done is enough and that it is time to move to next phase: small-scale clinical trials.

Thesecond moratorium should occur when the first small-scale clinical trials have been performed. Then one should wait a couple of years, maybe many years, to find out about the risk of viral infection. Presumably, the transplanted patients should be under monitoring and some restrictions. When - and if all analysis have been madeand the risk for infections is deemed low enough it is time to move to a wider clinical use.
However, it must be extremely difficult to put the second evaluative moratorium proposed by Bach and his cowriters into effect. If the first phase of small-scale clinical research on xenotransplantation has been relatively successful - and no spread of viral infection has yet been noted - it will be a superhuman task to hold back the demand from patients to be transplanted. It seems much more realistic to agree on the first part: moratorium until effective control regime has been put into use, but to disregard the second evaluative moratorium.

\section{Screening for PERV Infection}

After the research community was alerted to the danger of PERV infection, a screening study started to looking for signs of PERV infection amongthose 160 patient who has received (mainly) pig cell transplants. Recently published studies on two groups of Swedish patients - pig cell islet transplantation to diabetic patients and ex-vivo connection to pig kidneys - show no sign of PERV infection. (Heineine et al., 1998) However, in the diabetes case all the porcine cell islets died after some months and in the kidney case the pig kidney was outsidethebody of the patient and theconnection lasted some hours. Caution is recommended in the comments in one of the leading medical journals. (Stoye, 1998) The studies scanning xenotransplanted patients for infections are continuing.

Most probably, experiments on cell and tissue level will never answer the question about the risk of infection spreading from transplanted persons to others. The ultimate test is long term 
survival of xenografts in transplanted patients and looking for signs of viral infection. This is also recommended by Bach and his co-writers. Another way would be to infect primates with PERV and see what happens. Unfortunately for humans - it may not be possible to infect primate cells with PERV.

\section{Attempts to Regulate}

At present, work on guidelines for clinical trials of xenotransplantation is conducted in many countries. TheUK is one of the countries in the forefront of xenotransplantation and in 1997 an interim regulatoryauthority (UKXIRA) was established. All xenotransplantation procedures must be approved by the regulatory authority before they are allowed to start. This holds also for xenotransplantation used as "desperate measures" in the clinics. Many of the early xenotransplantation happened this way.

The UK regulatory agency has so far published a guidance on making proposals to conduct xenotransplantation on human subjects (UKXIRA, 1998) Unfortunately, some vital points are dangerously vague or missing in this document. The regulatory authority seems to presuppose that the principle of informed consent - as expressed in the Helsinki declaration ${ }^{3}$ - can beapplied in a straight forward way. For example, the guidance document states that research subjects in clinical xenotransplantation studies at any time may withdraw their consent and leave the protocol, presumably also after the transplantation has been performed. This will make monitoring for viral infection and possible restrictions in lifestylecompletely volun- tary and might pose a risk to the public.

What kind of restrictions and monitoring are needed? That xenotransplanted patients should be monitored life-long, should not give blood or donate organs are some not too severe restrictions often mentioned. But what about moving around freely in the population, what about sexual relationships, what about having children? And how long must these safeguards be in place?

In Sweden a parliamentary commission is presently working. Their task is to propose a legal framework for xenotransplantation trials. At present, the Swedish research groups active in the xenotransplantation field areabstaining from clinical trials. (As mentioned there has been clinical trials in Sweden) In November 1998 the Swedish regulatory authority for genetechnology organised a public conference on xenotransplantation. In the planning of the conference there was some worries that militant animal rights activists might protest. Nothing of that sort happened however.

\section{Xenotransplantation in the Political Arena}

Xenotransplantation has al so gained attention outside the sphere of regulatory bodies and the community of scientists and experts. Animal welfare organisations in different countries like the Uncaged campaignsin theU.K are heavily opposed to the technique and areactively campaigning against it. On the other side we have patient organisations like the Islet foundation in North America propagating for it. The issue have also been brought up to the political agenda in many countries. 1997 the Swedish green party presented a parlia- 
mentary bill (Mot 1997/ 98:So319) which demanded a moratorium on xenotransplantation research primarily based on the risk for retrovirus transmissions. However, this wasnot the only argument in the bill:

Apart from the surgeons' wish to save lives there are very strong commercial interests behind xenotransplantation. In 1995 it was estimated that the market for pig organs would be about six billion dollars and for immunosuppressors 10 billion dollars... Society's efforts ought to be directed at preventing medical damages which now are treated with transplantation. Preventive medicine and education on the importance of lifestyle for health must be given more resources.

The Swedish green party has, like their European counterparts, held a critical view of biotechnology and research on curative medical strategies and has instead propagated for preventive strategies. They have also a very negative view on the commercial involvement in research and technical development.

A very contrasting view was presented in a parliamentary bill (Mot 1997/98: Jo510) by the Swedish conservativeparty (a party advocating more room for market mechanisms and less for state involvement).

The great breakthroughs in gene technology are to be found in the medical arena... Gene therapy, effective AIDS therapy and xenotransplantation can be expected in the near future. The development of gene technology cannot be stopped. However, a small country like Sweden can decide to step aside from the development. The new and better products that will be a result of the gene technology can be imported. However, it will be wise to remember that the food and drug industry are important branches of business in this country whose future we don't want to risk. Furthermore, there is of little use to Sweden, that our researchers and industries efforts to develop new products adapted to our demands and conditions are rendered worseor impossible. Wehaveseen enough of brain drain and unemployment.

In this bill the possibilities with the new technique are at the forefront. As in the green party bill there is also a risk scenario but not a scenario which has anything to do with viruses. Instead it is the fear that we might lose in the economic competition with other countries that are highlighted.

Both the green party and the conservatives have used this kind of arguments in relation to other techniques in other contexts. Oneconclusion is, therefore, that the political interpretations, and reactions shown here, to a specific new techniquelikexenotransplantation are largely formed before the specific technique is introduced on the political agenda. The specific technique is not evaluated purely on the basis of its own merits and problems. The scheme to interpret and evaluate it is much more complexintegrating a wide range of values and norms about what the good society should be like.

In 1998 the Swiss people voted on the so called "Gen Schutz Initiative" presented by the Swiss green party, the social democrats and the women's party. In this initiative there was a call for a 10 year moratorium on xenotransplantation trials on humans. The initiative was backed by about 70 organisations including Greenpeace, Physicians Against Animal Experimentation, The Swiss Lutheran Women's League and the Swiss Catholic Women's League (Schatz, 1998). As in the Swedish case, the above 
mentioned arguments for and against xenotransplantation have been central in the Swiss debate.

As indicated before, thereis an organised opposition against xenotransplantation in the UK, foremost by organisations such as the Uncaged Campaigns and the society of Doctors and Lawyers for Responsible Medicine. The critics also have "voices" in the parliament. MP Norman Baker from the liberal democratic party has on several occasions criticised the development of xenotransplantation in the House of Commons. In march 1998, at the behalf of the Uncaged Campaigns, Baker presented a petition with morethan 100.000 signatures (House of Commons Hasard Debates for 31 March 1998 (pt 44) Xenotransplantation). Thepetition pointed at "the grave risk" for an epidemic among thegeneral population. It al so stated that thelikelihood of organ rejection will create suffering for the recipients of xenografts. Furthermore, the developing xenotransplantation field is said to ignore what could be more sensible and effective approaches to promoting health: preventive health measures and increase of the pool of human donors. Interestingly, animal welfare arguments seem to be of second importance in the argumentation. However, it is stated in the end of the petition:

Furthermore we believe that treating non-human animals as 'spare parts' factories is immoral and inhumane.

On January 21, 1999, Baker presented an Early Day Motion on xenotransplantation signed by 50 M Ps (Baker, 1999) An Early Day Motion is not generally debated in the parliament but more of a device to draw attention to an issue and elicit support for it by inviting other MPs to add their signatures. This motion was a reaction to a submission of an application for conducting a clinical trial to UKXIRA. It stated the following:

That this house... notes that, despite the theoretical benefits to transplant patients, there are major scientific obstacles and hazards to public health in particular, the potential of introducing a new viral pathogen into the wider population, which remain to be addressed; observes that the required legal sanctions to enforce the UKXIRArecommended surveillance regimes for any recipients of animal tissue are currently absent; recognises serious ethical and animal welfare concerns generated by the practice; acknowledges theexistence of widespread public unease regarding xenotransplantation, as evidenced by opinion polls and petitions; and in light of these gaps in scientific knowledge, regulatory powers and the absence of informed public consent, calls upon the Government to withhold permission for human xenotransplantation trials pending unequivocal evidence of the microbiological safety and clinical effectiveness of xenotransplantation, and categorical public consent for the commencement of human trials and, subsequent to theseconditions being satisfied, the introduction of the necessary legislation to ensure public health.

Wewould arguethat in theUKasin Sweden and Switzerland the risk of retroviral infectionsto the general population has become a rhetorical resource for the opponentsto xenotransplantation in the UK. By calling it a rhetorical resourcewe areindicating that the perceived risk was not the cause of opposition in the first place. This is instead based on animal rights or animal welfare arguments that might not convince the general public in the same way as arguments about public health risks. 


\section{Xenotransplantation in Surveys}

The issue of xenotransplantation has been addressed in several surveys during the 1990s. Thesestudies have examined either particular groups, i.e., patients waiting for a transplant, medical personnel, attitudes toward xenotransplantation (Mohacsi et al., 1995; 1997; Arundell \& McKenzie, 1997; Ward, 1997; Coffman et al., 1998; Julvez et al., 1999) or the attitudes of a more general population (ThePartnership for Organ donation, 1993; National Kidney Foundation, 1998; Melich, 1998; Macer, 1998). Some of these studies were conducted on the behalf of patient organisations. In Sweden a survey, not yet published, was conducted in 1998 as part of the ongoing investigations of regulatory requirement.

It is difficult, not to say impossible, to draw any general or unambiguous conclusions from the studies mentioned above. Surveys of transplant patients often show high acceptance but there are exceptions (Mohacsi et al., 1997). The largest study of a general population in thismatter, the Eurobarometer 46.1 surveying 15 European countries, showed a low public acceptance of xenotransplantation. All of the above mentioned studies can of course be criticised from different points of view. Somehave very small samples, are poorly presented and lack a proper analysis of the results. They also confirm theold maxim that the answers surely are dependent on the framing of the questions. ${ }^{4}$

A common argument in cases of public non-acceptance of or resistance to new technologies is what have been called 'the knowledge deficit' explanation. According to this argument therea- sons behind resistance are scientific illiteracy and/ or irrationally held beliefs. This kind of argument is also reflected in the discussions about the results in the studies mentioned above:

Despite living in an era in which many
scientific advances have occurred, we
humans still have primitive emotions.
The ability of humans to incorporate
things outsideourselves and retain our
identity is not accepted as a given by
all of our transplant patients or their
families. Theremay besimilar difficulty
in incorporating organs from new
sources such as animals for fear of ac-
quiring the donor's personality traits
and/ or diseases (Coffman et al., 1998).

The knowledge deficit argument was also used at an international conference on xenotransplantation in New York arranged by The OECD and The New York Academy of the Sciences. Here, Michael Oborne, deputy director at the OECD's Directoratefor Science, Technology and Industry made a parallel between the development of recombinant DNA technique and xenotransplantation. During the 1970s there was a strong public resistance to recombinant DNA techniques resulting in a temporary moratorium. Today, according to Oborne, this resistance is gone as the public has learned more about the technique and got used to it. The Canadian medical ethicist Bartha Maria Knoppers argued at the sameconference, that a new technique like xenotransplantation must be more exposed in the public debate. According to her, the public's negative reactions to the cloned sheep Dolly were due to it being unprepared (Gordon, 1998)

We will not argue that knowledge doesn't matter to the question whether or not one is prepared to accept a new 
techniquelikexenotransplantation. But the knowledge deficit explanation is in our view much too limited to explain the different attitudes to xenotransplantation held by different groups in society. A strategy only aimed at 'educating the public' will probably fail. There is today a lot of research showing that lay peoplearenot passive receivers of expert information and a growing literature criticising the knowledge deficit explanation. (Wynne, 1991; Davison et al., 1997.) In the words of John Ziman:

What they pick up is not simply a filtered version of formal scientific knowledge: its meaning is actively constructed by the processes and circumstances under which it is communicated and received (Ziman,1991:101).

In their review of risk communication studies, Turner and Wynne, points out that a new technology, its benefits and risks are interpreted from a complex, multilayered set of social, cultural and institutional factors. Theoutcome of the response will according to them depend on how the technique appears to influence the recipients' sociocultural identity, their constellation of moral values and trusted social networks and relationships (Turner \& Wynne, 1992: 124). In the case of xenotransplantation some of the deepest beliefs about what it is to be a human being appears to be contested. In an interview study of 24 young well-educated Athenians, Papagaroufali (1997) found that no one was prepared to accept an organ from a transgenic pig. Such organs were considered unnormal or unnatural. Another interview study conducted on the ten Swedish diabetic patients who had undergone pancreatic cell islet xenotransplantation showed the great ambivalence by these patients towards xenotransplantation. (Lundin, 1999)

Another important issue in understanding reactions to a new technology, is the trust the public put in the institutions trying to implement it. As indicated below, wethink thisiscentral in the case of xenotransplantation.

In the first survey of the general American population's attitudes toward xenotransplantation therewere marked differences between ethnic groups. The white population was the most willing to accept it, the Afro-American the least. It is known that the Afro-American patients on the average have to wait longer to get a human transplant. To some extent this has been explained by the fact that this group also shows a lower donation rate. There are not organs enough matching the Afro-American patients' HLA system. Thisin its turn is explained by the fact that Afro-Americans do not donate organs in the same extent as do the general American population. But these explanations lead only to the next problem. Why do Afro-Americans show a lower donation rate? In a study by Callender et al. (1995), five answers to this question were suggested:

- A lack of renal disease and transplantation awareness

- Religious myths, misperceptions and superstition

- A lack of trust in health care providers and the health administrative process

- A fear that signing organ donor cards might change the emphasis from lifesaving priority to organ donor priority

- A fear that the racism which AfroAmericans experience on a daily basis in life, would remain after death and that all organs donated 
from this group would go to white people

Thefirst two answersareconsistent with the knowledge deficit argument, the other three are pointing to something else. Here the issue of transplantation is interpreted and reconstructed from the social circumstancesunder which many Afro-Americans live in the US today. It is a context in which they experience discrimination in many spheres in social lifeand wheremedical care resourcesare unequally distributed according to ethnicity and social class. Most Afro-American also distrust the authorities. It is not hard to extrapolatefrom this situation to the xenotransplantation case. There is today no guidelines how to distribute xenografts, according to which principles and what the costs will be (Chao \& Cooper, 1997). Will a xenotransplant be better than a human one?Will the whites receivethebest kind of transplantswhile the Afro-Americans will be left with lower quality?With thisin mind, onecan understand why this group show low acceptance.

Regulating bodies both at a national and an international level arguethat one must consider the voice of the public in the process of implementing xenotransplantation in clinical practice. One way to let the public voice be heard has traditionally been, as in the Swedish case, to conduct a survey. We think that this strategy yields a very limited perspective on why the public view the xenotransplantation technique - or any other technique - in certain ways. Specially, the actors, with their different vested interests, behind the surveys must beconsidered to bean integral part of the process and structure to assess xenotransplantation.

\section{The Public and the Risks and Benefits of Xenotransplantation}

A very important element in the public reaction to xenotransplantation is how the public perceive the risk associated with thetechnique. Obviously, an important element is also how benefits are perceived. A very low benefit will make even asmall risk unattractive, whilelarge benefits might make risks more acceptable. "Risk" and "benefit" are no easy terms to apply and it might make a difference how risks and benefits are distributed.

It is well established that "technical" risks are only one aspect of what forms the public perception of a new technology. (Turner \& Wynne, 1992) The technical risks in xenotransplantation focus on two aspects. The risk for the public is therisk for retrovirusinfection, whilethe primary risk for the individual in need of an organ is the risk of immunological rejections. A considerable work is at present directed towards these two kinds of risks.

There are further risks for an individual patient in need of a transplant. There will presumably - if we assume xenotransplantation is able to pass its first tests - for some period be both animal organsand human organsinvolved in transplantation. Most probably, they will not in general be equally good. The risk for a particular patient is to be allocated to the worst alternative. That might happen becauseyou are discriminated against in the national health system (some other groups will get preferential treatment) or that the patient cannot pay to get the best. The insurance companies in the USwith their managed health care systems might insist that 
whether or not a person will receivea pig or a human organ should depend on what you pay for your insurance. The introduction of xenotransplantation in clinical setting might make the health care system more unequal.

Heroic attempts have been made to prohibit the marketing of human cells, tissue and organs. Even in the US buying and selling human organs for transplantation is prohibited. The general idea is donation. Organs for transplantation should begifts. Most probably, pig organs will be on the market. (They already are for food purpose.) There are already large pharmaceutical companies interested in marketing the pig organs. There is obviously a risk that commercialisation will moveinto transplantation. The public might react against this aspect in the way they react against "patents on life".

On the other hand, if xenotransplantation turns out to be as good as allotransplantation, there might bea large supply - for those who can pay. The immediate "objective" shortage of organs for transplantation mayend. Buta socioeconomically based shortage may appear instead. Really successful xenotransplantation might turn out to be pose a twofold threat to national health systems. First, if transplantation still is covered by the national health insurance, the great supply of commercially priced pig organs paid for by the state together with the trend that an increasing amount of illnesses can betreated by transplantation, may causea heavy burden to the health care budget. Second, if the national systems cannot afford to much xenotransplantation, there will probably be a two tiered system. One for ordinary citizens with longqueues - like the present day allotransplantation and one for rich people with immediate access to organs when they are needed. Whether or not this prospect is a risk or a benefit might depend on your general political orientation - and on whether or not you think you will be rich.

Turner and Wynne stress that an important dimension in the public risk perception is the implicit perceptions of social control. This is another important dimension of risk perception.

...people judge risk according to their perception of its controlling agents: if these agents have a social track record of secrecy, arrogance and incompetence, or if they appear to dominate supposedly independent regulatory bodies and the policy-making process, it is hardly surprising if peopletreat the risks as greater than those recognised in calculations of physical magnitudes of risks which are based on tacit assumptions that the institutional context does not matter. (Turner $\&$ Wynne, 1992: 123)

In thiscase the health sector is probably less distrusted by the public than many other areas. So if xenotransplantation mainly is handled as a health issue the public might develop a more relaxed view with regard to risks than if themain actors are the big pharmaceutical and biotechnological enterprises. Our guess is that the public tends to regard the health sector as more congenial to produce benefits for many than the private sector, which will primarily produce benefits above all for the shareholders.

On theother hand, theBSE crises and the public reaction against genetically modified food point in another direction. The public seems to be less comfortable with the monitoring and regulating agencies. Xenotransplantation is 
of course- likegenetically modified food -incorporation of "non-human" genetic material in our bodies. ${ }^{5}$ Like BSE and AIDS viral infections from xenotransplantation may spread to the general population.

\section{Concluding Remarks}

Xenotransplantation is an evolving medical technique whose outcome it is today impossible to predict. There are still lot of scientific/technical problems before the technique can be applied in ordinary clinical treatment There are risks and benefits with the new technology. The medical community and the public probably differ regarding what the risks and benefits are. There is a risk that the regulatory framework will rely to exclusivelyon themedical experts and disregard the other dimensions of public risks as outlined above.

As xenotransplantation is an evolving technology in its early phase we think it would be interesting to study how the public understanding of risks and benefits evolves and interacts with technical break-through and regulatory attempts.

\section{Notes}

1 Being members of the biomedical project BIO-CT 97-2242 supported by the European Commission we have attended several meetings when strategies for studying the details of these mechanisms have been discussed.

2 Work is going on looking for pigs without PERV.

3 Originally adopted by the World Medical Association in 1964 (in Helsinki) and amended several times, this declaration can besaid to be ethical framwork for conducting medical research on humans.

4 For a more detailed review (in Swedish), see Persson 1998a. An English version was presented at the EASST meeting in Lissabon 1998 (Persson 1998b)

5 Eating in general is of course incorporating non-human genetic material into our bodies. The belief is that traditional genetic material from non-modified food is more friendly to our bodies than material from genetically modified food.

\section{References}

Arundell, M. A. \& McKenzie, I. F. C.

1997 "The acceptability of pig organ xenografts to patients awaiting a transplant." Xenotransplantation 4: 62-66

Bach, F. H., Fishman, J. A., Daniels, N., Proimos, J., Anderson, B., Carpenter, C. B., Forrow, L., Robson, S. C, \& Fineberg, H. V.

1998 "Uncertainty in xenotransplantation: Individual benefit versus collective risk." Nature Medicine 4:141-44

Baker, N.

1999 EDM 233 Xenotransplantation, http:/ / edm.ais.co.uk/

Butler, U.

1998 "Last chance to stop and think on risks of xenotransplants." Nature 391: 320324

Chao, S. J. \& Cooper, D. K. C.

1997 "Legal implications for xenotransplantation." Xenotransplantation 4: 132-139

Coffman, K. L., Sher, L., Hoffman, A., Rojter, S., Folk, P., Cramer, D. V., Vierling, J., Villamel, F., Podesta, L., Demetrou, A. \& Makowka, L. 1998 "Survey Results of Transplant Patients' Attitudes on Xenografting." Psychosomatics 39: 379-383

Davison, A., Barns, I \& Schibeci, R.

1997 "Problematic Publics: A Critical Review of Public Attitudes to Biotechnology". Science, Technology \& Human Values 22: 317-348 
Denner, J.

1998 "Immunosuppression by Retroviruses: Implications for Xenotransplantation" Annals of the New York Academy of Sciences 862: 75-86

Gordon, A. T.

1998 International Issues in Transplantation, Biotechnology Including the Use of non-human Cells, Tissues and Organs. The Islet Foundation, http:// www.islet.org

Heneine, W., Tibell, A., Switzer, W. M. Sandstrom, P., Rosales, G. V., Mathews, A., Korsgren, O., Chapman, L. E., Folks, T. M. \& Groth, C. G.

1998 "No evidence of infection with porcine endogenous retrovirus in recipients of porcine islet-cell xenografts". Lancet 352: 695-99

House of Commons

1998 Hansard Debates for 31 March (pt 44) Xenotransplantation, http:// www. parliament.the-stationary-office.co. uk/

Julvez, J., Tuppin, P. \& Cohen, S.

1999 "Survey in France of response to xenotransplantation." Lancet 343: 726

Lundin, S.

1999"TheBoundless Body: Cultural Perspectives on Xenotransplantation". Ethnos 64:5-31

Macer, D.

1998 Attitudes to Biotechnology in New Zealand and Japan in 1997, http:// www.biol.tsukuba.ac.jp/macer/ biotechnnzj

Melich, A.

1998 Eurobarometer 46.1: Modern Biotechnology, Privacy on Computer Networks, and the Common European Currency, October-November 1996, (computer file). Brussels, Belgium: INRA (Europe) (producer), 1997. Koeln, Germany: Zentralarchivfür Empirische Sozialforschung. Ann Arbor MI: Interuniversity Consortium for Political and Social Research (distributors), 1998
Mohacsi, P. J., Blumer, C. E., Quine, S. \& Thompson, J. F.

1995 "Aversion to xenotransplantation." Nature 378: 438

Mohacsi, P. J., Thompson, J. F., Nicholson, J. K. \& Tiller, D. J.

1997 "Patients attitudes to xenotransplantation." Lancet 349: 1031

Motions in the Swedish Parliament

1997/ 98:So319 av Gudrun Lindvall och Eva Goës $(\mathrm{mp})$ Xenotransplantationer

1997/ 98:J o510 av Bertil Persson $\mathrm{m}$ fl (m) Genteknikens möjligheter

Novak, K.

1998 "US FDA to issue new rules on xenotransplantation". Nature Medicine 4: 876

Patience, C., Takeuchi, Y. \& Weiss, R. A.

1997 "Infection of human cells by an endogenous retrovirus of pigs." Nature Medicine 3: 282-286

Patience, C., Patton, G. S., Takeuchi, Y., Weiss, R. A., McClure, M. O., Rydberg, L. \& Breimer, M.E.

1998 "No evidence of pig DNA or retroviral infection in patients with short-term extracorporeal connection to pig kidneys". Lancet 352: 699-701

Platt, J.

1998 "New directions for organ transplantation." Nature 392, supplement: 11-17

Persson, A.

1998a "Att överskrida gränser. Om xenotransplantation, risker och människouppfattning." VEST 11; 31-60

1998b "Transgressing boundaries: Ethical and Social Dimensions of Xenotransplantation" Paper presented at EASST conference, Lisboa October 1 - 31998 Schatz, G.

1998 "The Swiss Vote on GeneTechnology." Science 281: 1810- 1811

Stoye, J.

1998 "No clear answers on safety of pigs as tissue donor source." Commentary, Lancet 352:666-67 
Turner, G. \& Wynne, B.

1992 "Risk communication-a literature review and some implications for biotechnology." Pp. 109-141 in Durant, J. (ed.), Biotechnology in public - a review of recent research. London: Science Museum

UKXIRA

1998 Guidanceon making proposals to conduct xenotransplantation on human subject. UKXIRA.

Ward, E.

1997 "Attitudes to xenotransplantation." Lancet 349: 1775

Wynne, B.

1991 "Knowledge in Context." Science, Technology \& Human Values 16:111-121

Ziman, J.

1991 "Public Understanding of Science." Science, Technology \& Human Values 16: 99-105

Stellan Welin and Anders Persson

Centre for Research Ethics,

Göteborg University,

Göteborg, Sweden 